\title{
Listening to Islamic Praises (Dzikr) is More Effective in Reducing Perioperative Anxiety Levels when Compared to Nature-Based Sounds in Muslim Patients Undergoing Surgery Under Regional Anaesthesia
}

\author{
Samsudin $A^{a}$, Yahya $N^{a}$, Wan Mat $W R^{a}$, Masdar $A^{a}$, Liu $C Y^{a}$, Izaham $A^{a}$ \\ aDepartment of Anaesthesiology \& Intensive Care, Universiti Kebangsaan Malaysia Medical Centre (UKMMC), \\ Jalan Yaacob Latif, Bandar Tun Razak, 56000 Kuala Lumpur, Malaysia.
}

\section{ABSTRACT}

Introduction: Many studies have investigated the effects of music on perioperative anxiety and its implication on anaesthetic practice, however there are limited number of studies reported for religious or spiritual intervention in this aspect. We investigated the effects of listening to Islamic praises (Dzikr) and nature-based sounds delivered via headphones as non-pharmacological interventions for perioperative anxiety. Materials and Methods: Sixty-three Muslim patients scheduled for elective lower limb surgery under regional anaesthesia were randomly assigned to listen to Dzikr (Group A), nature-based sounds (Group B) or given headphones without any sounds (Group C). Anxiety levels were assessed using a visual analogue scale for anxiety (VAS-A). Physiological responses (mean arterial pressure, heart rate and respiratory rate) as well as patients' overall satisfaction level were documented. Results: Patients in Group A demonstrated statistically significant lower VAS-A scores compared to those in Group B and C at 30-minutes after skin incision ( $p=0.002$ and $p=0.001$ respectively) and at the end of the surgery $(p=0.028$ and $p<0.001$ respectively). Patients in Group A recorded significantly higher satisfaction levels compared to those in Groups B $(p=0.038)$ and C ( $p=0.001)$. No significant differences were seen for the physiological responses, nor was there any additional anxiolytic requirement among the three groups. Conclusion: Listening to Dzikr among Muslim patients was more effective in reducing perioperative anxiety levels when compared to nature -based sounds, in patients who had undergone lower limb surgery under regional anaesthesia.

KEYWORDS: perioperative anxiety, regional anaesthesia, Islamic praises, Dzikr, nature-based sounds

\section{INTRODUCTION}

Patients scheduled for surgical procedures often experience significant levels of anxiety which can negatively influence psychological health and 2 delay recovery postoperatively if poorly managed. ${ }^{1}$ Elevated levels of anxiety may be associated with larger doses of anaesthetic requirement, a greater peri- and postoperative reliance on analgesics, increased catecholamine secretion, poor wound healing and prolonged hospital stay. ${ }^{2,3} \mathrm{~A}$ study on

\section{Corresponding Author:}

Dr. Nurlia Yahya,

Department of Anaesthesiology \& Intensive Care, Universiti Kebangsaan Malaysia Medical Centre (UKMMC), Jalan Yaacob Latiff, Bandar Tun Razak, 56000 Kuala Lumpur, Malaysia.

Tel no: +6039145 5783

E-mail: nurlia@ppukm.ukm.edu.my patients who had local, plexus or regional anaesthesia found that the incidence of anxiety was $23 \%$ on arrival to the operating theatre, $35 \%$ during induction of anaesthesia and $15 \%$ at the start of surgery. ${ }^{4}$ Sights of surgical and technical instruments as well as sounds of alarms and other equipment used in the operating theatre were also found to increase anxiety level intraoperatively. ${ }^{5}$ Pharmacological interventions such as sedatives or anxiolytics are often used to alleviate patients' anxiety, however they are not free from side-effects. Non-pharmacological interventions may serve as alternative methods in reducing patients' anxiety and may decrease potential unwanted effects of pharmacologic agents such as over-sedation and respiratory depression. ${ }^{6}$ Several studies have shown that passively listening to music via headphones in the perioperative setting can be 
beneficial in reducing anxiety, pain and sedative requirements such as propofol or midazolam during spinal anaesthesia. ${ }^{7,8,9,10,11}$

One of the non-pharmacological measures that may be used to reduce perioperative anxiety is spiritual or religious intervention such as listening to Islamic praises (Dzikr). Dzikr, or remembrance of Allah, are words of praise and glory to Allah, that can either be recited aloud or in silence to bring about a peaceful state of mind. ${ }^{12}$ Listening to nature-based sounds was shown to be effective in alleviating patients' anxiety in the perioperative ${ }^{13,14}$ as well as in the intensive care settings. ${ }^{15,16}$

Although there has been a growing interest in research on music, religious and spiritual interventions as non-pharmacological interventions to reduce anxiety in the last few decades, there are limited studies investigating the effects of Dzikr and nature-based sounds on anxiety and physiological response during surgery under regional anaesthesia. The purpose of this study therefore was to investigate the effects of listening Dzikr and naturebased sounds on perioperative anxiety levels, and haemodynamic and respiratory parameters, in Muslim patients undergoing lower limb surgery under regional anaesthesia.

\section{MATERIALS AND METHODS}

This prospective, single-blinded, randomised controlled study was conducted after obtaining approval from the Research Committee of the Department of Anaesthesiology \& Intensive Care, Universiti Kebangsaan Malaysia Medical Centre (UKMMC) and the Medical Research \& Ethics Committee, UKMMC (FF-2017-351).

Sixty-three Muslim patients aged between 20 and 70 years of age with American Society of Anesthesiologists (ASA) physical status class I or II scheduled for elective lower limb surgery with an expected surgical duration of two hours or less under regional anaesthesia were recruited into this study. Patients with hearing disabilities, neurological disorders, psychiatric illness and those who were on regular anxiolytics or sedative medications were excluded from this study. Recruitment of patients, study explanation and obtainment of written consent were done a day prior to surgery by the primary investigator.
Patients were fasted for at least six hours prior to surgery and oral midazolam $3.75 \mathrm{mg}$ or $7.5 \mathrm{mg}$ were given as premedication at $10 \mathrm{PM}$, the night prior to surgery. Patients were randomised using a computer-generated random number sequence to receive either Dzikr (Group A), nature-based sounds (Group B) or headphones without any sounds (Group C or control group).

In the operating room, standard anaesthetic monitoring which included continuous electrocardiography, non-invasive blood pressure and pulse oximeter were applied on all patients. Heart rate (HR), mean arterial pressure (MAP), respiratory rate (RR) and visual-analogue scale for anxiety (VAS-A) score were recorded prior to the procedure of regional anaesthesia and these were taken as baseline values. Neuraxial blockade was performed either at L3/L4 or L4/L5 level under aseptic technique to achieve a loss of sensation from T8-T10 dermatomes and below for all patients. Haemodynamic and respiratory parameters were recorded again after adequacy of blockade was established, and thereafter at 10-minute intervals until the end of the surgery.

Once adequacy of blockade was established, an over -the-ear occlusive headphone connected to a portable audio player was placed on the patients. The earpieces of the headphones were cleaned with alcohol wipes before they were applied over the patients' ears. The assigned audio materials were played in continuous loops (except for Group C) from the time of application of headphones until removal of headphones at the end of the surgery prior to transferring patients out of the operating room. The volume of the audio player was adjusted according to the individual patient's comfort level but set with a maximum volume limit on the audio player of 70 decibels $(\mathrm{dB})$, which was considerably lower than the permissible exposure limit of $85 \mathrm{~dB}$ for 8 hours per day as established by the National Institute for Occupational Safety and Health. ${ }^{17}$ Only the assessor (the attending anaesthetist) was blinded to the type of audio material that their patients received.

The audio player was inspected by an anaesthetic nurse or a second anaesthetist who was not blinded to the randomisation at 15-minute intervals to ensure that it was on continuous play and had not stopped inadvertently. The audio player was 
wrapped in an occlusive material and inspection was done out of the assessor's sight to ensure that the assessor remained blinded throughout the study. The second VAS-A score was recorded at 30-minutes after skin incision. Intravenous (IV) midazolam in $1 \mathrm{mg}$ boluses was given to patients who were disruptive towards the process of surgery based upon the attending anaesthetist's assessment or upon patients' request. Patients who needed conversion to general anaesthesia were dropped out of the study.

The final VAS-A score was recorded after removal of headphones at the end of the surgery, prior to transferring the patient out of the operating room. At the recovery area, haemodynamic and respiratory parameters were recorded again at 10 minutes post-operatively. Patients' overall satisfaction level was evaluated at the end of the study in the recovery area prior to being discharged to the ward.

\section{Assessment and instruments}

Auditory materials used in this study were selected tracks from Munajat Sufi album by Ustaz Abdullah Fahmi (InTeam Records, 2016) for Group A and sounds of water rippling and birds chirping from Soothing Nature-based Sounds: River in the Shire by The Honest Guys (The Honest Guys Ltd., 2015) for Group B. Patients in Group C received headphones without any sounds or music. Headphones and audio player used in this study were Sony ${ }^{\circledR}$ MDR ZX310 over-the-ear headphones and Sony ${ }^{\circledR}$ Walkman ${ }^{\circledR}$ NWZB183F respectively.

The visual analogue scale for anxiety (VAS-A) was used to measure anxiety levels in this study which correlates significantly with the more widely used methods such as Spielberger's State-Trait Anxiety Inventory for state-anxiety (STAI-S) ${ }^{18}$ and Amsterdam Preoperative Anxiety Information Scale (APAIS). ${ }^{19}$ The VAS-A scale was presented as a 100 $\mathrm{mm}$ horizontal line ranging from the far left of the scale which was anchored by the statement 'not anxious at all', to the far right of the scale which was anchored by the statement 'maximum anxiety'.

Patients were asked to mark their level of anxiety on the scale with a pen. Scores were derived by measuring the distance in millimetres from the far-left edge of the line to the mark made by patients. The simplicity of the VAS-A allowed a quick evaluation of patients' anxiety level and served as a convenient tool in clinical practice when limited time was available for questioning as in the intraoperative setting.

Patients' satisfaction level of overall perioperative experience was measured using a visual analogue scale (VAS satisfaction) which had been validated in a study by Brokelman et al (2012)..$^{20}$ The scale used was anchored by the statement 'no satisfaction' on the far left of the scale while the far right of the scale was anchored by the statement 'extreme satisfaction'.

\section{Statistical Analysis}

The sample size was calculated using the 'Power and Sample Size Calculation' (PS) software program using the independent $t$-test derived from the mean score of STAI-S and standard deviation based on the study by Rejeh et al (2016). ${ }^{13}$ The VAS-A and the STAI-S was significantly correlated $(r=0.5, p=0.01)$, demonstrating concurrent validity. ${ }^{18}$ The power of the study was set at $95 \%$, a value of 0.05 , standard deviation $(\sigma)$ value of 11.16 and effect size $(\delta)$ of 14.28. Initial calculation of sample size for each group was 17 patients. After taking into consideration the possibility of a $20 \%$ drop-out rate, 21 patients were recruited into each group.

All statistical data were analysed using IBM SPSS Statistics $^{\circledR}$ for Windows, Version 20.0 (IBM Corp., Armonk, NY). Descriptive statistics were used to summarise patients' demographic data. Skewness and kurtosis methods were used to test the assumption of normality. To detect significant difference among groups, one-way analysis of variance (ANOVA) followed by Tukey HSD test were used for analysis of parametric data, Kruskal-Wallis test followed by Mann -Whitney $U$ test were used for non-parametric data and Pearson's chi-square test was used for categorical data.

To analyse significant change along various time points, two-way repeated measures ANOVA was used for parametric data (VAS-A scores), while Friedman's test followed by Wilcoxon signed-ranks test and Kruskal-Wallis were used for non-parametric data (MAP, HR, and RR). A $p$ value of less than 0.05 was considered statistically significant unless stated otherwise. 
anaesthetic exposure among the three groups as

A total of 63 Muslim patients were recruited into seen in Table I. Mean duration of study intervention this study. There were no significant differences seen in demographic characteristics and previous was comparable among Groups A, B and C (153.2 \pm 54.0 minutes, $144.6 \pm 47.6$ minutes and $148.9 \pm 42.0$ minutes respectively, $p>0.846$ ).

Table I: Patients' demographic characteristics and previous anaesthetic exposure

\begin{tabular}{|c|c|c|c|c|c|}
\hline Characteristics & $\begin{array}{l}\text { Total } \\
(n=63)\end{array}$ & $\begin{array}{l}\text { Group A } \\
(n=21)\end{array}$ & $\begin{array}{l}\text { Group B } \\
(n=21)\end{array}$ & $\begin{array}{l}\text { Group C } \\
(n=21)\end{array}$ & $p$ values \\
\hline Age (years) & $51.8 \pm 15.4$ & $50.1 \pm 16.1$ & $52.4 \pm 14.9$ & $52.9 \pm 15.9$ & $0.832^{\mathrm{a}}$ \\
\hline $\begin{array}{l}\text { Gender } \\
\text { Male } \\
\text { Female }\end{array}$ & $\begin{array}{l}34(54 \%) \\
29(46 \%)\end{array}$ & $\begin{array}{l}11(52.4 \%) \\
10(47.6 \%)\end{array}$ & $\begin{array}{l}12(57.1 \%) \\
9(42.9 \%)\end{array}$ & $\begin{array}{l}11(52.4 \%) \\
10(47.6 \%)\end{array}$ & $0.938^{\mathrm{b}}$ \\
\hline $\begin{array}{c}\text { ASA } \\
\text { I } \\
\text { II }\end{array}$ & $\begin{array}{l}21(33.3 \%) \\
42(66.7 \%)\end{array}$ & $\begin{array}{l}8(38.1 \%) \\
13(61.9 \%)\end{array}$ & $\begin{array}{l}7(33.3 \%) \\
14(66.7 \%)\end{array}$ & $\begin{array}{l}6(28.6 \%) \\
15(71.4 \%)\end{array}$ & $0.807^{b}$ \\
\hline $\begin{array}{l}\text { Previous anaesthetic } \\
\text { exposure } \\
\text { Yes } \\
\text { No }\end{array}$ & $\begin{array}{l}36(57.1 \%) \\
27(42.9 \%)\end{array}$ & $\begin{array}{l}10(47.6 \%) \\
11(52.4 \%)\end{array}$ & $\begin{array}{l}13(61.9 \%) \\
8(38.1 \%)\end{array}$ & $\begin{array}{l}13(61.9 \%) \\
8(38.1 \%)\end{array}$ & $0.558^{\mathrm{b}}$ \\
\hline $\begin{array}{l}\text { Education level } \\
\text { Primary school } \\
\text { Secondary school } \\
\text { College or University }\end{array}$ & $\begin{array}{l}8(12.7 \%) \\
34(54.0 \%) \\
21(33.3 \%) \\
\end{array}$ & $\begin{array}{l}3(14.3 \%) \\
12(57.1 \%) \\
6(28.6 \%) \\
\end{array}$ & $\begin{array}{l}2(9.5 \%) \\
13(61.9 \%) \\
6(28.6 \%) \\
\end{array}$ & $\begin{array}{l}3(14.3 \%) \\
9(42.9 \%) \\
9(42.9 \%) \\
\end{array}$ & $0.759^{b}$ \\
\hline
\end{tabular}

Values are expressed as mean \pm standard deviation or frequency (percentage).

a $p$-values using one-way ANOVA; ${ }^{\mathrm{b}} p$-values using Pearson's chi-square test

There was no significant difference in baseline VASA scores among the three groups as shown in Table II. There was a significant change over time in VAS-A on the basis of group assignment demonstrated by a statistically significant interaction between the audio groups and time on VAS-A scores, $F_{2.78,83.41}=6.57, p=0.001$, partial $\eta^{2}=0.180$.

Following intervention, patients in Group A demonstrated statistically significant lower VAS-A score compared to those in Groups B and $C$ at 30 minutes after skin incision $(p=0.002$ and $p=0.001$ respectively) and at the end of the surgery $(p=0.028$ and $p<0.001$ respectively). As for patients in Group $B$, there was significantly lower VAS-A scores seen only at the end of surgery $(p=0.002)$, when compared to patients in Group C.

There was no significant difference in the number of patients who required additional anxiolytics intraoperatively among the three groups. In patients who received additional anxiolytics, total dose of IV midazolam required per patient was comparable among the three groups.

Table II: Mean VAS-A scores at baseline (VAS-A baseline), 30-minutes after skin incision (VAS-A 30) and at the end of the surgery (VAS-A end) and additional intraoperative anxiolysis requirement

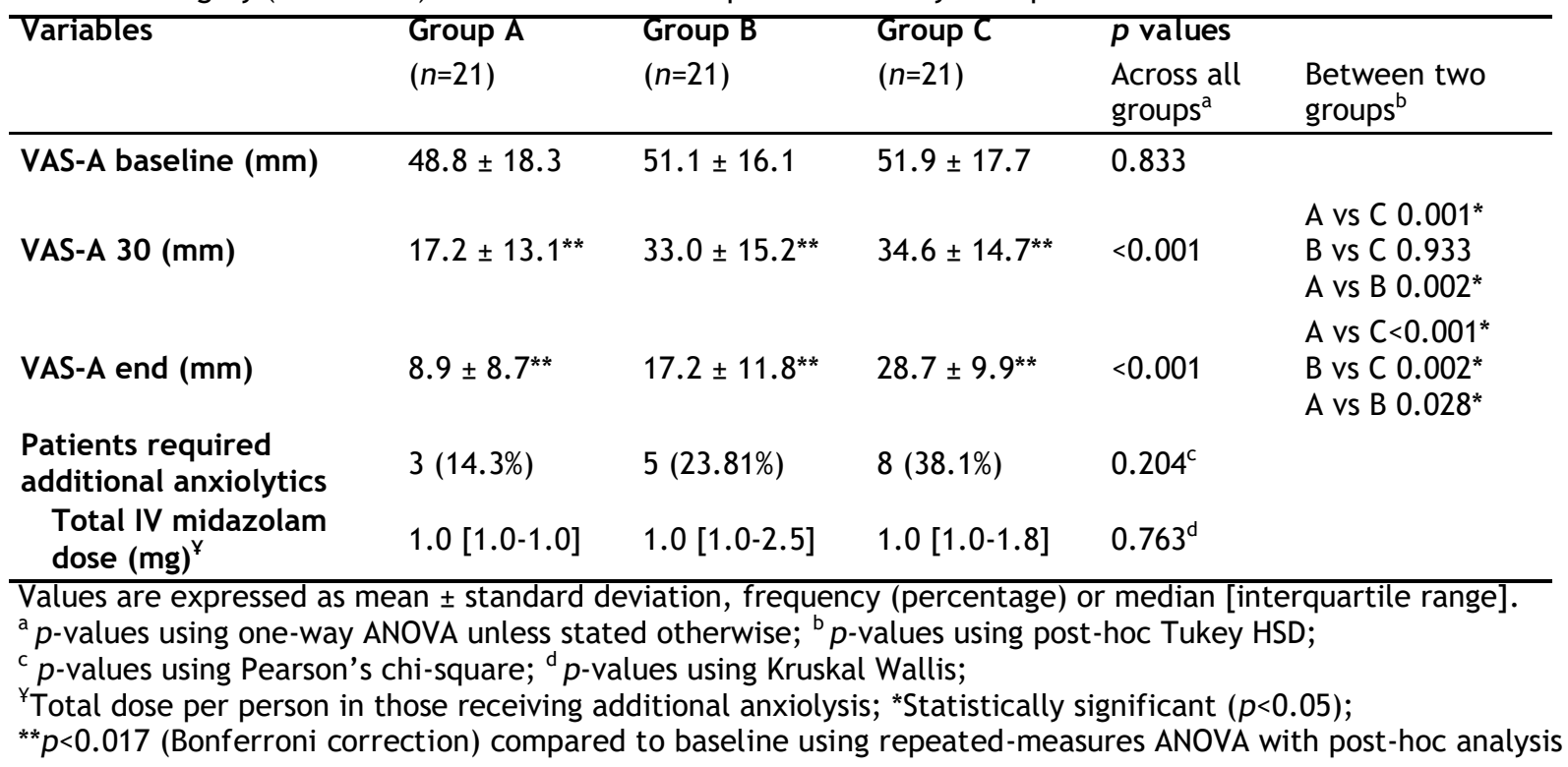


There was no significant difference in baseline MAP among the three groups. Comparison of median MAP and median reduction of MAP from baseline among the three groups did not show any significant difference (Figure 1).

There was no significant difference in baseline HR among the three groups. Significantly lower median HR was seen at 60-minutes in Group A compared to Group B $(p=0.013)$. Median HR and median change of $H R$ from baseline at all other time points were comparable among the three groups (Figure 2).
There was no significant difference in baseline RR, median RR or in median change of RR from baseline among the three groups (Figure 3 ).

Patients in Group A recorded significantly higher mean VAS satisfaction scores compared to Group B $(87.4 \pm 8.6 \mathrm{~mm}$ vs $80.7 \pm 8.3 \mathrm{~mm}, p=0.038)$ and Group C $(87.4 \pm 8.6 \mathrm{~mm}$ vs $79.4 \pm 9.1 \mathrm{~mm}, p=0.010)$. VAS satisfaction scores were comparable between Groups B and C $(80.7 \pm 8.3 \mathrm{~mm}$ vs $79.4 \pm 9.1 \mathrm{~mm}$, $p=0.872$ ).

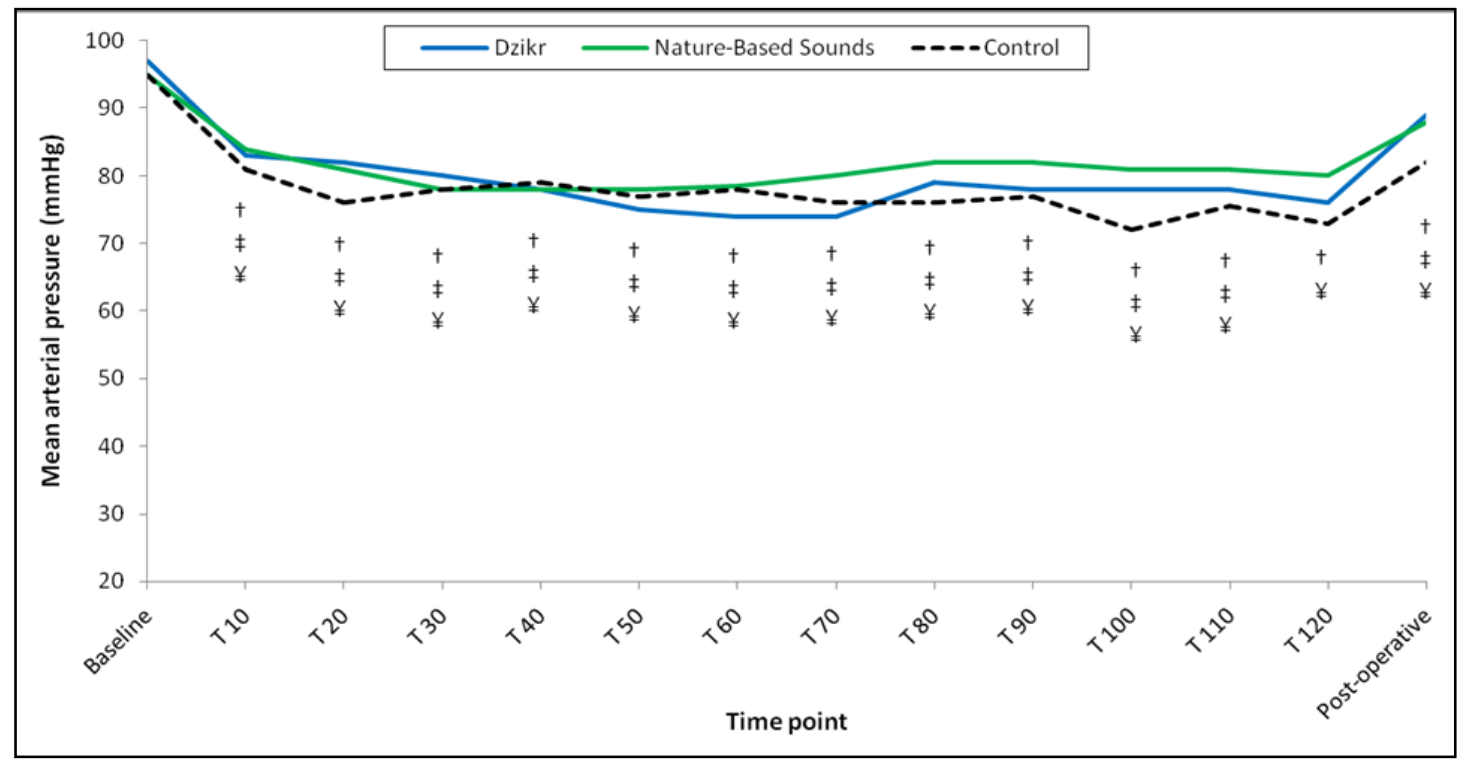

T10-T120: time points after start of intervention (in minutes)

${ }^{\dagger} p<0.0038$, significant difference compared to baseline in Dzikr group (Wilcoxon signed-rank test) ${ }^{\ddagger} p<0.0038$, significant difference compared to baseline in nature-based sounds group(Wilcoxon signed-rank test) ${ }^{\ngtr} p<0.0038$, significant difference compared to baseline in control group (Wilcoxon signed-rank test)

Figure 1: Comparison of mean arterial pressure trend over time among three groups

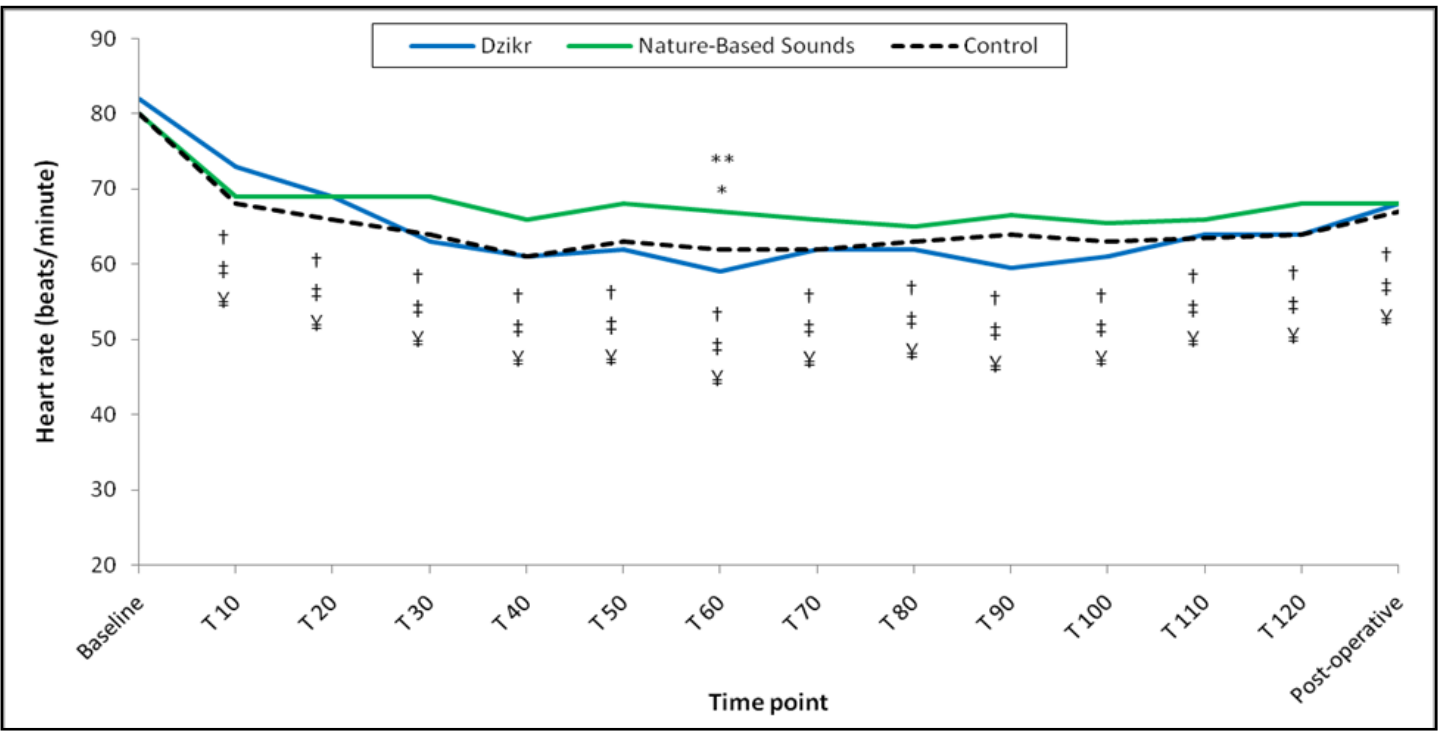

T10-T120: time points after start of intervention (in minutes)

${ }^{\dagger} p<0.0038$, significant difference compared to baseline in Dzikr group (Wilcoxon signed-rank test)

${ }_{p}^{\ddagger} p<0.0038$, significant difference compared to baseline in nature-based sounds group(Wilcoxon signed-rank test) ${ }^{7} p<0.0038$, significant difference compared to baseline in control group (Wilcoxon signed-rank test)

${ }^{*} p<0.05$, significant difference among three groups (Kruskal-Wallis test)

${ }^{* *} p<0.017$, significant difference Dzikr vs nature-based sounds group (Mann-Whitney $U$ test)

Figure 2: Comparison of heart rate trend over time among three groups 


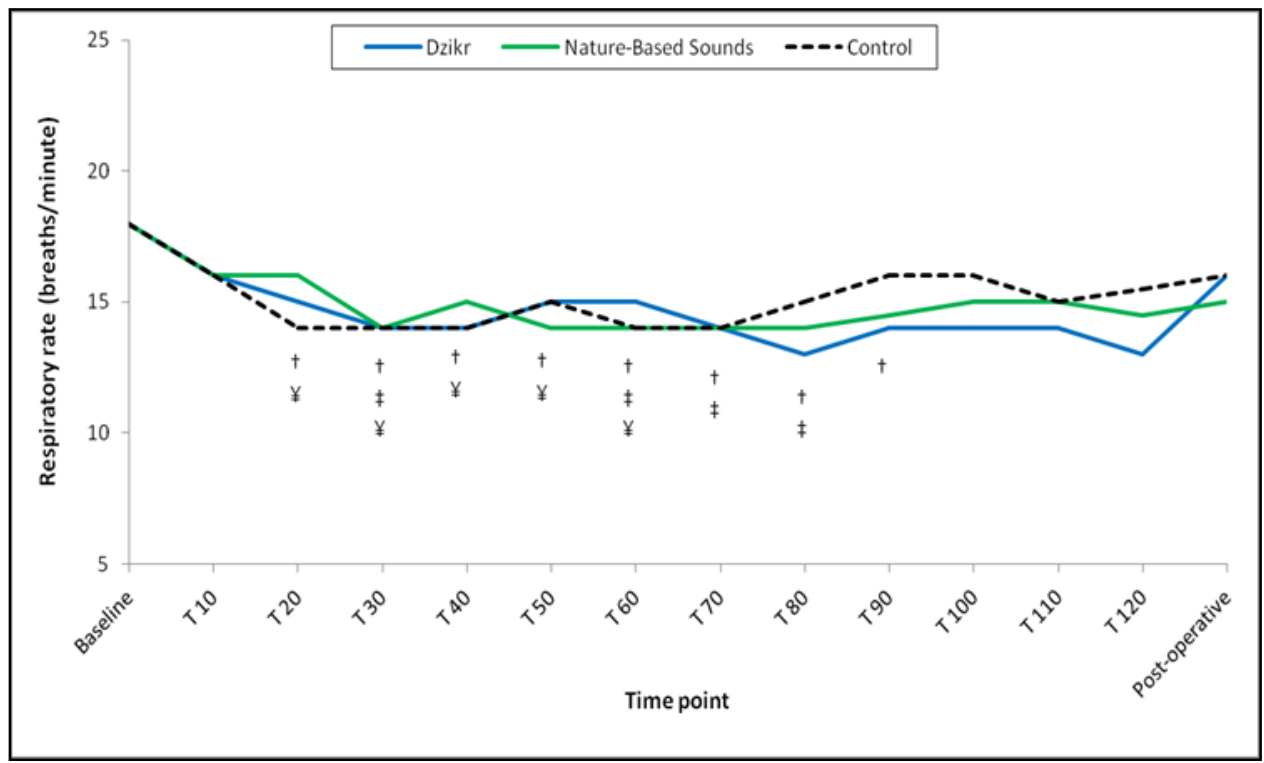

T10-T120: time points after start of intervention (in minutes)

${ }^{\dagger} p<0.0038$, significant difference compared to baseline in Dzikr group (Wilcoxon signed-rank test)

${ }^{\ddagger} p<0.0038$, significant difference compared to baseline in nature-based sounds group(Wilcoxon signed-rank test)

${ }^{¥} p<0.0038$, significant difference compared to baseline in control group (Wilcoxon signed-rank test)

Figure 3: Comparison of respiratory rate trend over time among three groups

\section{DISCUSSION}

Our study showed that Muslim patients who had undergone lower limb surgeries under regional anaesthesia while listening to either Dzikr or naturebased sounds resulted in lower perioperative anxiety levels compared to those who did not listen to anything at all. However, when comparing between the 2 groups, the patients in the Dzikr group had a greater reduction in anxiety levels throughout the study period. No significant differences were seen with regards to the haemodynamic and respiratory responses following intervention when compared across all groups.

Our findings were consistent with several studies which reported that music was associated with lower anxiety scores when compared to the control group. ${ }^{21,22,23,24,25}$ Findings from two systematic reviews on the effects of music intervention on anxiety also reported that music (which include nature-based sounds and religious chanting) had a consistent and statistically significant reduction on anxiety. ${ }^{26,27}$ A common theory regarding the anxietyreducing effects of music or audio intervention is that they act as a distracter, helping patients to focus their attention away from negative stimuli or stressful events to something pleasant and soothing. ${ }^{7}$ Elimination of external noise further enhances the clarity of music when delivered via headphones, thus helping patients to better channel their thoughts to the audio intervention itself. Therefore, the combination of sound isolation and the presence of a distracter may help explain why Dzikr and nature-based sounds were shown to be more effective in lowering-anxiety compared to wearing headphones alone.

In our study, patients in the Dzikr group demonstrated significantly lower anxiety levels compared to the nature-based sounds group at 30 minutes after skin incision and at the end of the surgery. A systematic review by Nilsson (2008) found that tempo of the music was the most important factor for relaxation and recommended slow and flowing music at about 60 to 80 beats per minute to be used for music interventions in clinical practice. ${ }^{7}$ Dzikr, which is a form of religious chant, contains words and phrases often recited in a repetitive, melodious manner and at a slow tempo, in contrast with nature-based sounds which are non-lyrical and do not have an organised tempo or melody. We postulated that the difference in the characteristics of the two audio materials used may explain the distinctive effects on anxiety between the Dzikr and nature-based sounds groups in our study.

With regards to the use of Dzikr listening as a form of religious-based audio intervention, limited studies are available for comparison. Our findings were 
consistent with a study by Beiranvand et al (2014), who investigated the effect of listening to 20 minutes of Dzikr on anxiety and haemodynamic changes after caesarean section under spinal anaesthesia, which showed a significantly lower incidence of anxiety with no difference in blood pressure, heart rate as well as respiratory rate seen in patients who listened to Dzikr compared to those who did not. ${ }^{28}$ Two other studies that used Dzikr in the form of verbal-recitation by patients themselves either in the preoperative or postoperative periods ${ }^{29,30}$ showed a significant reduction in anxiety level compared to those in the control group, which was consistent with findings of our study.

A study by Zulkurnaini et al (2012), showed that listening to Quran recitations could result in a more relaxing condition due to a greater increase in alpha band on electroencephalogram when compared to listening to classical music. ${ }^{31}$ Alpha waves are associated with a state of wakeful calmness and relaxation with closed eyes..$^{31,32}$ They also suppress extraneous brain activity thus blocking distracting stimuli. ${ }^{33}$ As the content of Dzikr includes verses taken from the Quran or hadith (a narrative record of the sayings or customs of Prophet Muhammad SAW and his companions), increases in alpha band power may explain the anxiety-lowering effect of Dzikr in our study. Furthermore, a recent study by Farah et al (2018) even showed significant reduction in postoperative pain scores in patients who listened to Dzikr during general anaesthesia which further supports the beneficial effects of religious-based audio intervention. ${ }^{34}$

With regards to the effect of listening to music on physiological responses such as blood pressure, heart rate and respiratory rate, our findings were similar with several randomised controlled trials in which no significant difference was seen when comparing the music groups (which included nature -based sounds and religious songs) to the control groups. ${ }^{22,24,28}$ However there were other contradicting studies which found significant difference in physiological responses in the music groups when compared to control groups. ${ }^{14,21}$ Nevertheless, findings from two systematic reviews showed that effects on physiological responses were actually inconsistent across multiple studies. ${ }^{14,26}$ Although increasing blood pressure, heart rates and respiratory rates are often regarded as physiological markers for anxiety, these physiological responses are also influenced by endocrine, metabolic and haematological changes caused by surgical stress depending on the extent of tissue trauma. ${ }^{35}$

Our study had some limitations. Firstly, this was a single-centre study conducted predominantly among Malay-Muslim patients, living in an urban area in Kuala Lumpur. Thus, geographical, cultural, or socioeconomic differences may limit the generalisability of our findings to other patients treated in different regions of the country itself and around the world. Secondly, audio materials used in this study were selected by the researcher and not by the patient and the duration of music was confined to the intraoperative period and did not include the preoperative or postoperative period. It has been suggested that music intervention may be most effective in reducing anxiety if patients could choose their preferred type of music ${ }^{14}$ and if the intervention was started preoperatively. ${ }^{26}$

Due to the diversity and lack of standardisation of protocols in previous studies, more studies are warranted to determine the optimal timing and duration of listening to Dzikr or nature-based sounds to bring about a positive effect on reduction of perioperative anxiety. We also suggest the use of active noise-cancelling headphones in future research for better attenuation of external auditory stimuli. In addition to passive noise isolation, active noise-cancelling headphones capture the ambient noise, process it and then generate a reverse waveform to counteract the ambient noise waveform. Patients in the control group would then be able to have significant reduction in hearing ambient noises in the study environment, while groups with intervention may listen to the intended audio material at lower and safer volumes. ${ }^{36}$

\section{CONCLUSION}

Listening to Dzikr was more effective in reducing perioperative anxiety levels when compared to nature-based sounds, in Muslim patients who had undergone lower limb surgery under regional anaesthesia.

\section{Conflict of interest}

None to declare. 


\section{ACKNOWLEDGEMENT}

We would like to express our gratitude to Puan Qurratu'aini Musthafa, a science officer in the Department of Anaesthesiology \& Intensive Care, UKM Medical Centre for her advice and assistance in the statistical analysis as well as all anaesthetic trainees and nurses who were involved in the data collection of this study.

\section{REFERENCES}

1. Brull R, McCartney CJ, Chan VW. Do preoperative anxiety and depression affect quality of recovery and length of stay after hip or knee arthroplasty? Can J Anaesth 2002; 49:109.

2. Berth H, Petrowski K., Balck F. The Amsterdam Preoperative Anxiety and Information Scale (APAIS) - the first trial of a German version. Psychosoc Med 2007; 4: 1-8.

3. Fell D, Derbyshire DR, Maile CJ, et al. Measurement of plasma catecholamine concentrations. An assessment of anxiety. $\mathrm{Br} \mathrm{J}$ Anaesth 1985; 57: 770-774.

4. Haugen AS, Eide GE, Olsen MV, et al. Anxiety in the operating theatre: a study of frequency and environmental impact in patients having local, plexus or regional anaesthesia. J ClinNurs 2009; 18:2301-2310.

5. Mitchell, M. 2008. Conscious surgery: influence of the environment on patient anxiety. $J$ AdvNurs. 64:261-271.

6. Griffin CE, Kaye AM, Bueno FR, Kaye AD. Benzodiazepine pharmacology and central nervous system-mediated effects. Ocshner J 2013; 13: 214-223.

7. Nilsson U. The anxiety and pain-reducing effects of music interventions: a systematic review. AORN Journal 2008; 87:780-807.

8. Hole J, Hirsch M, Ball E, Meads C. Music as an aid for postoperative recovery in adults: a systematic review and meta-analysis. The Lancet 2005; 386: 1659-1671.

9. Koelsch S, Fuermetz J, Sack U, et al. Effects of music listening on cortisol levels and propofol consumption during spinal anesthesia. Front Psychol 2011; 2:1-9.

10. Lepage C, Drolet P, Girard M, Grenier Y, DeGagné R. Music decreases sedative requirements during spinal anesthesia. AnesthAnalg 2001; 93: 912-916.
11. Ayoub CM, Rizk LB, Yaacoub Cl, Gaal D, Kain $\mathrm{ZN}$. Music and ambient operating noise in patients undergoing spinal anesthesia. AnesthAnalg 2005; 100: 1316-1319.

12. Sabiq S. Funerals and Dhikr. In: Fiqh us-Sunnah. Indianapolis: American Trust Publications, 1991: 100-101.

13. Rejeh N, Heravi-Karimooi M, Tadrisi SD, et al. The impact of listening to pleasant natural sounds on anxiety and physiologic parameters in patients undergoing coronary angiography: a pragmatic quasi-randomized-controlled trial. Complement TherClinPract 2016; 25:42-51.

14. Bradt J, Dileo C, Shim M. Music interventions for preoperative anxiety. Cochrane Database Systematic Reviews 2013 [Online]. Available at: https://doi.org/10.1002/14651858.

CD006908.pub2. Accessed February 15, 2019.

15. Aghaie B, Rejeh N, Heravi-Karimooi $M$, et al. Effect of nature-based sound therapy on agitation and anxiety in coronary bypass graft patients during weaning of mechanical ventilation: a randomised controlled trial. Int J Nurs Stud 2014; 51: 526-538.

16. Saadatmand V, Rejeh N, Heravi-Karimooi M, et al. Effect of nature-based sounds' intervention on agitation, anxiety and stress in patients under mechanical ventilator support: a randomised controlled trial. Int J Nurs Stud 2013; 50: 895-904.

17. National Institute for Occupational Health and Safety. Criteria for a recommended standard: occupational noise exposure (Revised criteria 1998). Ohio: DSSH (NIOSH) Publication, 1998

18. Chlan LL. Relationship between two anxiety instruments in patients receiving mechanical ventilator supports. J AdvNurs 2004; 48:493499.

19. Homzova P, Zelenikova R. Measuring perioperative anxiety in patients undergoing elective surgery in Czech Republic. Cent Eur J NursMidw 2004. 6:321-326.

20. Brokelman RBG, Haverkamp D, van Loon C, van Kampen A, Veth R. Validation of the visual analogue scale for patient satisfaction after total hip arthroplasty. EurOrthopTraumatol 2012; 3:101-105.

21. Ghiasi A, Keramat A. The effect of listening to Holy Quran recitation on anxiety: a systematic review. Iranian J Nursing Midwifery Res 2018; 23:411-420.

22. Uğraș GA, Yıldırım G, Yüksel S, et al. The effect 
of different types of music on patients' preoperative anxiety: a randomized controlled trial. Complement TherClinPract 2018; 31: 158163.

23. Wang SM, Kulkarni L, Dolev J, Kain ZN. Music and preoperative anxiety: a randomized, controlled study. AnesthAnalg 2002; 94: 14891494.

24. Johnson B, Raymand S, Goss J. Perioperative music or headsets to decrease anxiety. J PerianesthNurs 2012; 27: 146-154.

25. Jiménez-Jiménez $M$, García-Escalona A, MartínLópez A, De Vera-Vera R, De Haro J. Intraoperative stress and anxiety reduction with music therapy: a controlled randomized clinical trial of efficacy and safety. J VascNurs 2013; 31: 101-106.

26. Gillen E, Biley F, Allen D. Effects of music listening on adult patients' pre-procedural state anxiety in hospital. Int J Evid Based Healthc 2008; 6: 24-49.

27. Pittman S, Kridli S. Music intervention and preoperative anxiety: an integrative review. IntNurs Rev 2011; 58: 157-163.

28. Beiranvand S, Noaparast M, Eslamizade N, Seedikia $S$. The effects of religion and spirituality on postoperative pain, hemodynamic functioning and anxiety after cesarean section. Acta Med Iran 2014; 52: 909 915.

29. Hosseini M, Salehi A, Fallahi Khosknab M, Rokofian A, Davidson PM. The effect of a preoperative spiritual / religious intervention on anxiety in Shia Muslim patients undergoing coronary artery bypass graft surgery: a randomized controlled trial. J Holist Nurs2013; 31: 164-172.

30. Nasiri M, Naboureh A, Fayazi S. The effect of an Islamic praise (zikr) on postoperative anxiety of patients undergoing coronary artery bypasses graft surgery: a randomized clinical trial on Iranian Muslim Shia. Res Cardiovasc Med 2016; 6:1-7.

31. Zulkurnaini NA, Kadir RSSA, Murat Z, Isa $\mathrm{RM}$. The comparison between listening to AlQuran and listening to classical music on the brainwave signal for the alpha band. 2012 Third International Conference on Intelligent Systems, Modelling and Simulation. 2012. Available at: https://doi.org/10.1109/ ISMS.2012.60. Accessed February 2, 2019.

32. Abdullah AA, Omar Z. The effect of temporal
EEG signals while listening to Quran recitation. International Journal on Advanced Science, Engineering and Information Technology [Online]. 2011; 1:372. Available at: http:// dx.doi.org/10.18517/ijaseit.1.4.77. Accessed February 2, 2019.

33. Bonnefond $M$, Jensen $O$. Alpha oscillations serve to protect working memory maintenance against anticipated distracters. CurrBiol 2012; 22: 19691974.

34. Farah Syaza R, Nurlia Y, Nor Mohamad MD, Azarinah I, Wan Rahiza WM. The comparative effects of listening prayer recitation and music therapy intraoperatively on postoperative pain. International Medical Journal of Malaysia 2018; 17:107-116.

35. Quick CRG, Reed JB, Harper SJF, Saeb-Parsy K, Deakin $\mathrm{PJ}$, eds. Essential surgery: problems, diagnosis and management. $5^{\text {th }}$ ed. London: Churchill Livingstone, 2014

36. Belyi V, Gan WS. Integrated psychoacoustic active noise control and masking. Applied Acoustics. 2019 145:339-348. 